\title{
ORALIDADE E LETRAMENTO NA CONSTRUÇÃO DA PONTUAÇÃO
}

Lourenço Chacon*

\section{Introdução}

Trabalhos como os de Abaurre (1988; 1989; 1991; 1996; 1999), Abaurre e Cagliari (1985), Abaurre e Silva (1993), Abaurre, Fiad e Mayrink-Sabinson (1997), Cagliari (1993; 1998), Silva (1994) e Capristano (2003) mostram-se, a nosso ver, como particularmente significativos no contexto brasileiro, na medida em que têm permitido a detecção de importantes fatos da relação sujeito/ linguagem no processo lingüístico convencionalmente chamado de aquisição da escrita. Nosso destaque a esses trabalhos se deve, sobretudo, a vínculos que seus autores estabelecem entre fatos mais característicos da escrita, como a escolha de grafemas e as hipóteses de segmentação, e a intuição, por parte das crianças, de fatos fonético-fonológicos da língua (em sua dimensão segmental ou prosódica).

É nesse quadro de reflexão sobre as relações sujeito/linguagem na aqusição da escrita que incluiremos este nosso trabalho. Assim, dando prosseguimento a questões de algum modo já levantadas em trabalho anterior (cf. Chacon, 1999), mais uma vez nosso interesse se volta para a busca de fatos

* Universidade Estadual Paulista. chacon@marilia.unesp.br 
CHACON, L. Oralidade e letramento na construção...

lingüísticos possivelmente envolvidos na construção da pontuação por parte de crianças que iniciam seu processo de escolarização.

\section{Material e metodologia}

As marcas de pontuação que constituem o nosso corpus foram extraídas de 45 textos produzidos por três diferentes sujeitos (do gênero masculino, com idade média de sete anos) que freqüentaram uma mesma sala de primeira série do ensino fundamental na EMEF Dr. João Jorge Sabino - município de São José do Rio Preto (SP). Esses textos ( 15 de cada sujeito) foram produzidos em contexto escolar, entre os meses de fevereiro a outubro de 2000 , como resposta a 15 diferentes propostas temáticas estabelecidas pelo professor responsável pela sala. Escolhemos, a propósito, apenas textos de propostas temáticas das quais os três sujeitos participaram.

Por solicitação do professor, essas 15 diferentes propostas temáticas foram desenvolvidas com base em diferentes tipos de textos: ${ }^{1}$

\begin{tabular}{|l|c|}
\hline \multicolumn{1}{|c|}{ Proposta temática } & Data \\
\hline 01- O pirata (canção) & $+/-15 / 02 / 00$ \\
\hline 02- O doce (parlenda) & $+/-13 / 04 / 00$ \\
\hline 03- A foca (canção) & $01 / 05 / 00$ \\
\hline 04- Atirei o pau no gato (canção) & $19 / 05 / 00$ \\
\hline 05- A galinha/pássaro no céu (narrativa) & $05 / 06 / 00$ \\
\hline 06- O elefante e a bruxa (quadrinhos) & $12 / 06 / 00$ \\
\hline 07- O telefone (quadrinhos) & $29 / 06 / 00$ \\
\hline 08- Mamãe da rua (brincadeira) & $01 / 08 / 00$ \\
\hline 09- O cravo e a rosa (canção) & $02 / 08 / 00$ \\
\hline 10- O sapo (canção) & $08 / 08 / 00$ \\
\hline 11- A bruxa e seu cachorro (quadrinhos) & $+/-14 / 08 / 00$ \\
\hline 12- Se eu fosse uma pipa... (narrativa) & $+/-28 / 08 / 00$ \\
\hline 13- O elefante elegante (quadrinhos) & $11 / 09 / 00$ \\
\hline 14- A bruxa e o gato/natal (quadrinhos) & $+/-03 / 10 / 00$ \\
\hline 15- Sobre um bicho (narrativa) & $+/-15 / 10 / 00$ \\
\hline
\end{tabular}

1 O quadro do qual consta a enumeração das propostas e a descrição de como elas foram desenvolvidas foram extraídos do trabalho de Capristano (2003). 
As propostas 1, 2, 3, 4, 9 e 10 constituíram-se de reprodução (escrita) de peças do cancioneiro infantil e de uma parlenda. Em todas estas produções textuais, as crianças realizaram, previamente, algumas atividades ${ }^{2}$ com ênfase ora na forma gráfica das canções e parlenda apresentadas, ora em sua forma oral.

Com exceção do fragmento que constou da proposta 1, apresentada como parte das atividades que envolviam o tema carnaval e que visou apenas a escrita do texto pelas crianças, em todos os outros casos, o objetivo foi o de introduzir o estudo de uma letra do alfabeto. Assim, a segunda, terceira, quarta, nona e décima propostas foram pretexto para, respectivamente, o estudo das letras D, F, G, R e S. ${ }^{3}$

As propostas 6, 7, 11 e 14 tiveram como ponto de partida histórias em quadrinhos. Nestas propostas, a produção do texto seguia um procedimento bastante semelhante: a professora solicitava, de início, que as crianças contassem, oralmente, a história dos quadrinhos; após essa atividade oral, elas iniciavam a produção do texto. Nesse momento, a professora, geralmente, sugeria que as crianças não apenas contassem a história que se passava nos quadrinhos, mas, também, aquilo que poderia ter ocorrido após o término do último quadrinho. Infelizmente, não foi possível recuperar todas as sugestões feitas em todas as histórias.

Na proposta 5, a professora apresentou para as crianças um livro intitulado Que planeta é esse? ${ }^{4}$ A atividade tinha em vista que as crianças, inicialmente, imaginassem que iriam ouvir uma história. Embora a professora tivesse começado a contar a história (leu informações sobre o livro: nome dos autores, o lugar onde o livro havia sido produzido, características do livro - como o fato de ele ser composto apenas por ilustrações - etc.), a narração foi interrompida na primeira ilustração do texto. Após esta interrupção, a professora pediu às crianças que contassem, por escrito, a história que elas imaginavam que iria se desenrolar a partir da ilustração mostrada (um passarinho olhando, de uma nuvem, para a Terra, por meio de um microscópio).

2 As crianças, em geral, aprenderam, primeiramente, a cantar as canções e a declamar a parlenda sem apoio gráfico-visual. Posteriormente, cantaram, acompanhando-as em suas formas gráficas, e "montaram", em dois momentos diferentes - primeiro, sozinhas; depois, auxiliadas por cartazes feitos pela professora - as canções e parlenda apresentadas graficamente (numa espécie de quebra-cabeça).

3 Com esse propósito principal, foram, também, realizadas algumas atividades paralelas às já descritas anteriormente. Tais atividades envolveram uso da letra do alfabeto trabalhada: palavra cruzada, caça-palavras, ditado, listas de figuras e de palavras e, ainda, atividades em que as crianças deveriam separar as palavras de tais listas pela sílaba inicial. Os textos resultantes de cada proposta somente foram feitos após todas essas atividades.

4 RENNÓ, R. C. Que planeta é esse? São Paulo: FTD, 1996. 
Os textos resultantes da proposta 8 foram produzidos como parte das atividades referentes à disciplina de Educação Física. Durante todo o ano 2000, as crianças participaram de atividades que envolviam brincadeiras que elas mesmas haviam escolhido no início daquele ano. Nestas atividades, a cada semana, as crianças brincavam e descreviam (coletivamente) uma brincadeira daquelas que haviam sido listadas por elas. As produções coletivas seguiam um esquema de produção textual que consistia em: a) nome da atividade (Brincadeira de criança); b) nome da brincadeira; c) descrição do material utilizado para brincar; e d) explicação de como se brincava. No dia em que foram produzidos os textos que abrangem a proposta 8 , a professora solicitou, inicialmente, que um aluno lembrasse como funcionava a brincadeira. Logo em seguida, pediu que as crianças escrevessem individualmente como se desenvolvia a brincadeira selecionada (Mamãe da rua), com o propósito de, num momento posterior, a classe escolher uma versão para que todos a tivessem no caderno escolar.

Na proposta 12, as crianças deveriam escrever um texto imaginando como elas seriam se fossem uma pipa. A folha distribuída pela professora para que as crianças escrevessem seus textos trazia a frase Se eu fosse uma pipa..., que iniciava um texto a ser concluído pelas crianças.

Na proposta 13, as crianças deveriam, novamente, escrever uma história a partir de uma seqüência de quadrinhos. Esses quadrinhos acompanhavam um poema infantil intitulado "O elefante elegante" e foram retirados de um livro didático. ${ }^{5}$ Os quadrinhos parecem ter sido feitos para que as crianças os colocassem em ordem de acordo com a seqüência em que os fatos (ações) apareciam no poema, mas a professora não exigiu, nem mesmo sugeriu, que eles seguissem esta ordem. ${ }^{6}$

As produções escritas vinculadas à proposta 15 decorreram do trabalho com conteúdos de Ciências, especificamente aqueles que se referiam a seres vivos. No período que antecedeu essa produção escrita, as crianças estavam trabalhando, principalmente, com características dos animais e com distinções feitas com o

5 Não foi possível recuperar a referência bibliográfica do livro didático do qual os quadrinhos e o poema infantil intitulado "O elefante elegante" foram copiados, porque, da cópia utilizada para a atividade em questão, não constavam indicações bibliográficas.

6 No mesmo dia em que foi produzido esse texto, as crianças realizaram algumas atividades com o poema: a) leram individualmente; b) ouviram o poema lido pela professora e por alguns colegas; c) conversaram sobre o "enredo" do poema; d) copiaram o texto no caderno; e) responderam a algumas questões feitas pela professora vinculadas ao poema (Em quais lugares o elefante foi?/Como você imagina que o elefante é?/Que nome você daria para o elefante? Por quê?/Se o elefante tivesse uma namorada, como ela seria?); f) ilustraram o texto. 
intuito de classificá-los (macho/fêmea, domésticos/selvagens etc.). As crianças baseavam-se, para tanto, em pesquisas, recortes, colagens e, sobretudo, em textos didáticos retirados de livros destinados à primeira série do ensino fundamental. Nos textos resultantes da proposta em questão, as crianças deveriam escolher um bicho e escrever sobre ele. A professora não especificou qual tipo de texto as crianças deveriam privilegiar (se uma história, uma descrição, um diálogo etc.).

Como se pode observar, o conjunto dessas produções desenvolveu-se, pois, com base em três tipos mais específicos de textos, a saber:

- seis textos em versos (propostas 1, 2, 3, 4, 9 e 10);

- oito textos narrativos (propostas 5, 6, 7, 11, 12,13, 14 e 15);

- um texto de instrução (proposta 8).

\section{Exposição e discussão de resultados}

Feitas as considerações sobre circunstâncias de produção do material de que extraímos nossas marcas de pontuação, veremos de que modo organizamos os empregos dessas marcas nos textos de nossos três sujeitos. Nossos resultados serão inicialmente apresentados sob forma de cinco quadros. Neles, dois modos de organização de dados encontram-se presentes: a) por tipos de sinais ocorridos no conjunto dos sujeitos (quadro 1); b) por tipos de sinais e por quantidade de ocorrência em função de propostas temáticas, tanto no conjunto de sujeitos (quadro 2) quanto para cada um de nossos três sujeitos (quadros 3, 4 e 5).

Após a apresentação desses quadros, destacaremos o que nos pareceram ser as tendências principais dos resultados neles expostos.

QUADRO 1 - DISTRIBUIÇÃO DO TOTAL DE OCORRÊNCIA DOS SINAIS DE PONTUAÇÃO POR TIPO E POR SUJEITO

\begin{tabular}{|c|c|c|c|}
\hline SINAIS & SUJEITO 1 & SUJEITO 2 & SUJEITO 3 \\
\hline Ponto & 44 & 25 & - \\
\hline Vírgula & 15 & - & - \\
\hline Interrogação & 6 & 1 & 5 \\
\hline Exclamação & 7 & 5 & 22 \\
\hline Reticências & - & 1 & - \\
\hline Dois-pontos & 11 & 5 & 46 \\
\hline Travessão & 13 & 30 & - \\
\hline Aspas & 2 & - & 75 \\
\hline TOTAL & 98 & 67 & \\
\hline
\end{tabular}


CHACON, L. Oralidade e letramento na construção...

QUADRO 2 - DISTRIBUIÇÃO DA OCORRÊNCIA DE PONTUAÇÃO POR TIPO DE SINAL E POR PROPOSTA TEMÁTICA NO CONJUNTO DE SUJEITOS

\begin{tabular}{|c|c|c|c|c|c|c|c|c|c|c|c|c|c|c|c|c|}
\hline & $\mathrm{T}$ & $\mathrm{T}$ & $\mathrm{T}$ & $\mathrm{T}$ & $\mathrm{N}$ & $\mathrm{N}$ & $\mathrm{N}$ & $\mathrm{I}$ & $\mathrm{T}$ & $\mathrm{T}$ & $\mathrm{N}$ & $\mathrm{N}$ & $\mathrm{N}$ & $\mathrm{N}$ & $\mathrm{N}$ & $\mathrm{T}$ \\
$\mathrm{V}$ & $\mathrm{V}$ & $\mathrm{V}$ & $\mathrm{V}$ & & & & $\mathrm{B}$ & $\mathrm{V}$ & $\mathrm{V}$ & & & & & & $\mathrm{O}$ \\
\hline & $\mathrm{F}$ & $\mathrm{A}$ & $\mathrm{M}$ & $\mathrm{M}$ & $\mathrm{J}$ & $\mathrm{J}$ & $\mathrm{J}$ & $\mathrm{Ag}$ & $\mathrm{Ag}$ & $\mathrm{Ag}$ & $\mathrm{Ag}$ & $\mathrm{Ag}$ & $\mathrm{S}$ & $\mathrm{O}$ & $\mathrm{O}$ & \\
\hline$\cdot$ & - & - & 3 & - & 10 & 6 & 6 & 3 & - & - & 11 & 2 & 1 & 14 & 13 & 69 \\
\hline, & - & - & - & - & 2 & - & - & - & - & - & - & 3 & 1 & 1 & 8 & 15 \\
\hline$?$ & - & - & 4 & 1 & - & 1 & - & - & - & - & - & - & 1 & 1 & 4 & 12 \\
\hline$!$ & 3 & - & - & 1 & 1 & 1 & - & - & - & 2 & - & 1 & 3 & 2 & 20 & 34 \\
\hline$\ldots$ & 2 & - & - & 1 & - & - & - & - & - & - & - & - & - & - & - & 3 \\
\hline$:$ & - & - & - & - & - & - & - & 5 & - & - & - & - & 1 & 10 & - & 16 \\
\hline- & - & - & - & - & - & - & - & - & - & - & 11 & - & 37 & 12 & 29 & 89 \\
\hline “ & - & - & - & - & - & - & - & - & - & - & - & - & - & 2 & - & 2 \\
\hline & & & & & & & & & & & & & & & & \\
\hline to & 5 & - & 7 & 3 & 13 & 8 & 6 & 8 & - & 2 & 22 & 6 & 44 & 42 & 74 & 240 \\
\hline
\end{tabular}

\section{LEGENDA:}

1. ${ }^{\text {a }}$ linha do quadro = tipos de texto (TV: textos versificados; N: narrativa; IB: instrução de brincadeira)

2. ${ }^{a}$ linha do quadro = meses do ano (F: fevereiro; A: abril; M: maio; J: junho; Ag: agosto; S: setembro; O: outubro)

$\mathrm{TO}=$ total de ocorrências de sinais

to $=$ total de ocorrência de sinais por proposta temática

QUADRO 3 - DISTRIBUIÇÃO DA OCORRÊNCIA DE PONTUAÇÃO POR TIPO DE SINAL E POR PROPOSTA TEMÁTICA NO SUJEITO 1

\begin{tabular}{|c|c|c|c|c|c|c|c|c|c|c|c|c|c|c|c|c|}
\hline & $\mathrm{T}$ & $\mathrm{T}$ & $\mathrm{T}$ & $\mathrm{T}$ & $\mathrm{N}$ & $\mathrm{N}$ & $\mathrm{N}$ & $\mathrm{I}$ & $\mathrm{T}$ & $\mathrm{T}$ & $\mathrm{N}$ & $\mathrm{N}$ & $\mathrm{N}$ & $\mathrm{N}$ & $\mathrm{N}$ & $\mathrm{T}$ \\
$\mathrm{V}$ & $\mathrm{V}$ & $\mathrm{V}$ & $\mathrm{V}$ & & & & $\mathrm{B}$ & $\mathrm{V}$ & $\mathrm{V}$ & & & & & & $\mathrm{O}$ \\
\hline & $\mathrm{F}$ & $\mathrm{A}$ & $\mathrm{M}$ & $\mathrm{M}$ & $\mathrm{J}$ & $\mathrm{J}$ & $\mathrm{J}$ & $\mathrm{Ag}$ & $\mathrm{Ag}$ & $\mathrm{Ag}$ & $\mathrm{Ag}$ & $\mathrm{Ag}$ & $\mathrm{S}$ & $\mathrm{O}$ & $\mathrm{O}$ & \\
\hline$\cdot$ & - & - & 3 & - & 10 & 5 & 6 & 3 & - & - & 3 & 1 & 1 & 7 & 5 & 44 \\
\hline, & - & - & - & - & 2 & - & - & - & - & - & - & 3 & 1 & 1 & 8 & 15 \\
\hline$?$ & - & - & 3 & - & - & 1 & - & - & - & - & - & - & 1 & 1 & - & 6 \\
\hline$!$ & 1 & - & - & - & 1 & 1 & - & - & - & 1 & - & 1 & - & 2 & - & 7 \\
\hline$\ldots$ & - & - & - & - & - & - & - & - & - & - & - & - & - & - & - & - \\
\hline$:$ & - & - & - & - & - & - & - & 3 & - & - & - & - & 1 & 7 & - & 11 \\
\hline- & - & - & - & - & - & - & - & - & - & - & - & - & 4 & 9 & - & 13 \\
\hline “ & - & - & - & - & - & - & - & - & - & - & - & - & - & 2 & - & 2 \\
\hline & & & & & & & & & & & & & & & & \\
\hline to & 1 & - & 6 & - & 13 & 7 & 6 & 6 & - & 1 & 3 & 5 & 8 & 29 & 13 & 98 \\
\hline
\end{tabular}

\section{LEGENDA:}

1. ${ }^{a}$ linha do quadro = tipos de texto (TV: textos versificados; N: narrativa; IB: instrução de brincadeira)

2. ${ }^{\mathrm{a}}$ linha do quadro = meses do ano (F: fevereiro; A: abril; M: maio; J: junho; Ag: agosto; S: setembro; O: outubro)

$\mathrm{TO}=$ total de ocorrências de sinais

to $=$ total de ocorrência de sinais por proposta temática 
QUADRO 4 - DISTRIBUIÇÃO DA OCORRÊNCIA DE PONTUAÇÃO POR TIPO DE SINAL E POR PROPOSTA TEMÁTICA NO SUJEITO 2

\begin{tabular}{|c|c|c|c|c|c|c|c|c|c|c|c|c|c|c|c|c|}
\hline & $\mathrm{T}$ & $\mathrm{T}$ & $\mathrm{T}$ & $\mathrm{T}$ & $\mathrm{N}$ & $\mathrm{N}$ & $\mathrm{N}$ & $\mathrm{I}$ & $\mathrm{T}$ & $\mathrm{T}$ & $\mathrm{N}$ & $\mathrm{N}$ & $\mathrm{N}$ & $\mathrm{N}$ & $\mathrm{N}$ & $\mathrm{T}$ \\
& $\mathrm{V}$ & $\mathrm{V}$ & $\mathrm{V}$ & $\mathrm{V}$ & & & & $\mathrm{B}$ & $\mathrm{V}$ & $\mathrm{V}$ & & & & & & $\mathrm{O}$ \\
\hline & $\mathrm{F}$ & $\mathrm{A}$ & $\mathrm{M}$ & $\mathrm{M}$ & $\mathrm{J}$ & $\mathrm{J}$ & $\mathrm{J}$ & $\mathrm{Ag}$ & $\mathrm{Ag}$ & $\mathrm{Ag}$ & $\mathrm{Ag}$ & $\mathrm{Ag}$ & $\mathrm{S}$ & $\mathrm{O}$ & $\mathrm{O}$ & \\
\hline$\cdot$ & - & - & - & - & - & 1 & - & - & - & - & 8 & 1 & - & 7 & 8 & 25 \\
\hline, & - & - & - & - & - & - & - & - & - & - & - & - & - & - & - & - \\
\hline$?$ & - & - & - & 1 & - & - & - & - & - & - & - & - & - & - & - & 1 \\
\hline$!$ & 1 & - & - & - & - & - & - & - & - & 1 & - & - & 3 & - & - & 5 \\
\hline$\ldots$ & 1 & - & - & - & - & - & - & - & - & - & - & - & - & - & - & 1 \\
\hline$:$ & - & - & - & - & - & - & - & 2 & - & - & - & - & - & 3 & - & 5 \\
\hline- & - & - & - & - & - & - & - & - & - & - & 11 & - & 10 & 3 & 6 & 30 \\
\hline “ & - & - & - & - & - & - & - & - & - & - & - & - & - & - & - & - \\
\hline & & & & & & & & & & & & & & & & \\
\hline to & 2 & - & - & 1 & - & 1 & - & 2 & - & 1 & 19 & 1 & 13 & 13 & 14 & 67 \\
\hline
\end{tabular}

\section{LEGENDA:}

1. ${ }^{a}$ linha do quadro = tipos de texto (TV: textos versificados; N: narrativa; IB: instrução de brincadeira)

2. ${ }^{a}$ linha do quadro = meses do ano (F: fevereiro; A: abril; M: maio; J: junho; Ag: agosto; S: setembro; O: outubro)

$\mathrm{TO}=$ total de ocorrências de sinais

to $=$ total de ocorrência de sinais por proposta temática

QUADRO 5 - DISTRIBUIÇÃO DA OCORRÊNCIA DE PONTUAÇÃO POR TIPO DE SINAL E POR PROPOSTA TEMÁTICA NO SUJEITO 3

\begin{tabular}{|c|c|c|c|c|c|c|c|c|c|c|c|c|c|c|c|c|}
\hline & $\mathrm{T}$ & $\mathrm{T}$ & $\mathrm{T}$ & $\mathrm{T}$ & $\mathrm{N}$ & $\mathrm{N}$ & $\mathrm{N}$ & $\mathrm{I}$ & $\mathrm{T}$ & $\mathrm{T}$ & $\mathrm{N}$ & $\mathrm{N}$ & $\mathrm{N}$ & $\mathrm{N}$ & $\mathrm{N}$ & $\mathrm{T}$ \\
& $\mathrm{V}$ & $\mathrm{V}$ & $\mathrm{V}$ & $\mathrm{V}$ & & & & $\mathrm{B}$ & $\mathrm{V}$ & $\mathrm{V}$ & & & & & & $\mathrm{O}$ \\
\hline & $\mathrm{F}$ & $\mathrm{A}$ & $\mathrm{M}$ & $\mathrm{M}$ & $\mathrm{J}$ & $\mathrm{J}$ & $\mathrm{J}$ & $\mathrm{Ag}$ & $\mathrm{Ag}$ & $\mathrm{Ag}$ & $\mathrm{Ag}$ & $\mathrm{Ag}$ & $\mathrm{S}$ & $\mathrm{O}$ & $\mathrm{O}$ & \\
\hline$\cdot$ & - & - & - & - & - & - & - & - & - & - & - & - & - & - & - & - \\
\hline, & - & - & - & - & - & - & - & - & - & - & - & - & - & - & - & - \\
\hline$?$ & - & - & 1 & - & - & - & - & - & - & - & - & - & - & - & 4 & 5 \\
\hline$!$ & 1 & - & - & 1 & - & - & - & - & - & - & - & - & - & - & 20 & 22 \\
\hline$\ldots$ & 1 & - & - & 1 & - & - & - & - & - & - & - & - & - & - & - & 2 \\
\hline$:$ & - & - & - & - & - & - & - & - & - & - & - & - & - & - & - & - \\
\hline- & - & - & - & - & - & - & - & - & - & - & - & - & 23 & - & 23 & 46 \\
\hline “ & - & - & - & - & - & - & - & - & - & - & - & - & - & - & - & - \\
\hline & & & & & & & & & & & & & & & & \\
\hline & & & & & & & & & & & & & & & & \\
\hline to & 2 & - & 1 & 2 & - & - & - & - & - & - & - & - & 23 & - & 47 & 75 \\
\hline
\end{tabular}

\section{LEGENDA:}

1. ${ }^{a}$ linha do quadro = tipos de texto (TV: textos versificados; N: narrativa; IB: instrução de brincadeira)

2. ${ }^{a}$ linha do quadro = meses do ano (F: fevereiro; A: abril; M: maio; J: junho; Ag: agosto; S: setembro; O: outubro)

$\mathrm{TO}=$ total de ocorrências de sinais

to $=$ total de ocorrência de sinais por proposta temática 
Encerrada essa nossa apresentação de resultados, exporemos, conforme antecipamos, o que nos pareceram ser as principais tendências que os dados, agrupados nesses quadros, nos mostram:

a) variação inter-sujeitos;

b) variação intra-sujeitos;

c) variação em função de tipos de textos;

d) aumento de marcas de pontuação ao longo do ano;

e) saliência do caráter gráfico da pontuação nas primeiras produções textuais;

f) percepção de conjunção não-isomórfica de elementos de várias naturezas lingüísticas nas estruturas delimitadas por sinais de pontuação.

Passemos, pois, ao levantamento de questões relativas a essas tendências.

No que se refere a (a), variação inter-sujeitos, os quadros 3, 4 e 5 permitemnos observar, respectivamente, uma distribuição de ocorrências de sinais de pontuação mais equilibrada no sujeito 1 , mais esparsa no sujeito 2 e mais concentrada nas primeiras e nas últimas propostas no sujeito 3 , com a exploração de sinais mais específicos em cada um desses dois momentos.

Se nos detivermos mais particularmente nos empregos do ponto e do travessão - os dois tipos de sinais mais utilizados, no conjunto, pelos sujeitos -, seus processos de emprego da pontuação mais singulares aparecem com maior nitidez. Em primeiro lugar, chama-nos a atenção a ausência total do ponto nos 15 textos do sujeito 3 , especialmente se vista em comparação com as 44 ocorrências desse sinal nos textos do sujeito 1 e com as 25 ocorrências nos textos do sujeito 2. Parece-nos que o sujeito 3 é mais sensível à propriedade de os sinais indiciarem fatos da oralidade, tais como a delimitação da estrutura dialógica e, nela, mais especialmente, a delimitação de atos de fala (manifestada pela larga ocorrência de travessão em apenas dois textos - como exemplificaremos logo abaixo) ou a demarcação de algumas de suas possíveis características prosódicas, tais como diferenças de contornos entonacionais (manifestada pela significativa ocorrência de pontos de exclamação e de interrogação). Se nossa hipótese tiver fundamento, a ausência do ponto decorreria, pois, de o sujeito 3, provavelmente, não estabelecer vínculos entre o emprego desse sinal e a demarcação de fatos da oralidade.

Mas chama-nos igualmente a atenção os diferentes modos de utilização desse mesmo sinal pelos sujeitos 1 e 2 . 
Com efeito, o ponto parece, para o sujeito 1 , estar mais vinculado à delimitação de parágrafos, independentemente de sua extensão, como se pode verificar no exemplo abaixo ${ }^{7}$ (proposta temática 5):

\author{
ERA UMA VEZ UM PASSARINHO QUE SE CHAMAVA PAU- \\ LO \\ PAULO ESTAVA NAS NUVENS POR QUE QUERIA VER O CÉU MAS \\ DE PERTO. \\ TODO DIA ELE IA NO CÉU COM SEU MICROSCOPIO PARA VER A TERRA. \\ PAULO SO NÃO VIAA TERRAL LÁ NA TERRA POR QUE ONDE MORAVAA- \\ VIA MUITOS GATOS!. \\ E PASSAROS ERA JUSTO O QUE OS GATOS GOSTAM. \\ O PAULO NEM QUERIA VER A CARA DO CHEFE DOS GATOS. \\ E PARAPIORAR UM DOS GATOS ESTAVA COMENDO UMA JOVEM PASSARI- \\ NHA. COM TRINTAE UMANOSERAPERFEITAPARAELEQUE VOUTOU PARA \\ A TERRA PARA SOCORELA. \\ PAULO DIZIA VEM SEUS GATOS MALVADOS EU VOU ACABAR COM \\ VOCÊS MAS OS GATOS SO QUERIAM COMER A POBRE PASSARINHA. \\ ENTÃO PAULO TEVE UMA GRADE IDEIA. \\ ELE CHAMOU A ATENÇÃO DE DOIS GATOS OS DOIS GATOS PULA \\ RÃO DIZENDO UM PASSARINHO ELE É MEU, MAS A IDEIA DOS GATOS \\ NÃO FOI MUITO BOA, ACABARÃO BATENTO A CABEÇA E CHAMOUA \\ ATENÇÃO DOS OUTROS GATOS. \\ TODOS OS GATOS SO QUIZERÃO SABER DE COMER O PAULO E DE- \\ IXARAM A FEMIA DE LADO QUE SE CHAMAVA KARINA. \\ QUANDO PAULO VUOL PARA A TERRA CHAMOU KARINA PARA O CÉ- \\ U KARINA ACEITOU O CONVITE PAULO E KARINA FORÃO PARA O CÉU E \\ VIVERÃO FELIZES PARA SEMPRE
}

Este e outros textos do sujeito 1 manifestam sua tendência de vincular o emprego do ponto à delimitação de parágrafos. No seu conjunto de 15 textos, raras foram as ocorrências desse sinal no interior de parágrafo. Por sua vez, o sujeito 2, inicialmente, emprega o ponto para delimitar grandes unidades textuais, que, no texto que virá a seguir - proposta 6 -, provavelmente, correspondem a fatos ocorridos antes e durante o casamento das personagens:

7 O texto será transcrito em letra maiúscula, já que, no original, figura com letra de forma. Além disso, neste e nos demais exemplos que se seguirão, as quebras nos finais de linha correspondem a quebras feitas pelos sujeitos nos textos originais. 
o elefente ficoa paxonado para bruxa fico efeis eles ficofe e um dia e fois no praia no dia que es tava sou. e fono dia docava mei to e na ora de coloca a lir lianca e de pois fonaora de sibeja a brxa fico a sutada

Especialmente no segundo semestre, de modo irregular, novas tendências podem ser observadas no sujeito 2, como a de delimitar por ponto porções textuais correspondentes a unidades como orações ou períodos, e, ainda, a de delimitar, como o sujeito 1, unidades como parágrafos.

Já no que se refere ao travessão, a tendência mais constante do sujeito 1 é a de demarcar turnos de diferentes personagens, como nos mostra o exemplo abaixo (proposta 13):

O elefate Bruno fugil do bosqui e foi para o

Ponto de táxi e coando o taxi chegou o ele-

fante disse

- para a cidade.

chegado lá foi pra loja de roupa e perguntou

- tem o tamanho G G?

a dona da loja achou a ropa sertapra ele e disse:

sim tem sim

- coanto custa

disse o elefante

$-5,90$

disse a vendedora,

A mesma tendência se observa no sujeito 2 (proposta 15):

e os três porquinho ermão saiu correndo

e eles viu uma moça e a moça falou

- porque vocês esta correndo.

- por que o lobo mal esta correndo 
atrás da gente.

Dice o terceiro porquinho o segundo

porquinho falou.

- Vamos ir na faserda do vovô

- Vamos mais rápido.

Dice o primeiro porquinho.

Já a tendência principal do sujeito 3 é a delimitação de diferentes atos de fala, não importa se de uma mesma ou de diferentes personagens, como se vê no exemplo abaixo (proposta 13):

- agora vou naiscola - di jato - profossora - fou

lafora - não vose não vailavora nãu ${ }^{8}$

Como se pode observar pelos fatos levantados nos exemplos, embora em contato com os mesmos tipos de sinais, conforme destacamos a propósito do ponto e do travessão, os três sujeitos parecem estabelecer relações mais singulares com as possibilidades de emprego dos mesmos sinais.

Passemos, agora, a abordar questões relativas a (b), variação intrasujeitos. A mudança de critério norteador do emprego de ponto que observamos no sujeito 2 e que destacamos logo acima - a saber, a passagem da delimitação de unidades textuais para a de unidades como parágrafos, períodos e orações possibilita perceber que nem sempre um mesmo sujeito mantém o mesmo tipo de relação com um mesmo tipo de sinal de pontuação.

Além disso, se voltarmos ao quadro 3, veremos que, dos 15 empregos de vírgula do sujeito 1,8 deles ocorreram em um único texto (correspondente à proposta 15). Por sua vez, das 8 propostas de produção de textos narrativos, em apenas 2 desses textos o mesmo sujeito empregou o travessão, num total de 13 ocorrências. Observe-se, por fim, que 4 delas se deram no texto 13 e 9 no texto 14 . lá fora não.

8 - agora vou na escola - que chato - professora - vou lá fora - não, você não vai 
Fato semelhante pode ser verificado no sujeito 2. Se retomarmos o quadro 4, notaremos que, de suas 5 ocorrências de ponto de exclamação, 3 delas se verificaram em um único texto (correspondente à proposta 13).

Mais notória ainda é a emergência do travessão em textos do sujeito 3. Como é possível observar no quadro 5, de suas 46 ocorrências desse sinal, 23 delas aconteceram no texto correspondente à proposta 13 e outras 23 no texto correspondente à proposta 15 .

Esses fatos nos levam a confirmar tendências já observadas por Abaurre, Fiad e Mayrink-Sabinson (1997), de que determinados fatos da linguagem adquirem, em momentos específicos do processo de aquisição da escrita, particular saliência para os aprendizes da língua escrita. Em nosso caso, é possível observar que essa saliência se dá tanto em relação ao tipo de sinal quanto em relação a seu momento particular de ocorrência. Desse modo, ao assumirem como próprio (Soares, 1998) um objeto em construção - a escrita -, a significação que a pontuação adquire para os sujeitos em seus contatos iniciais com a prática da escrita certamente está bastante vinculada a diferentes tipos de relações que esses sujeitos estabelecem com esse seu objeto em construção em momentos específicos de sua inserção por práticas de letramento, tais como, por exemplo, aquelas que envolvem o trabalho com o material didático e com outros tipos de materiais de escrita, principalmente em situação escolar.

Continuando nossa discussão, passemos agora a levantar questões a propósito de (c), variação em função de tipos de textos. A esse respeito, interessantes fatos podem ser destacados se retomarmos dados expostos no quadro 2 .

Como se pode observar, os textos narrativos que compõem o nosso material de análise, sobretudo em função de um grande número de situações de discurso direto criadas por seus autores, mobilizaram grande ocorrência de travessão e significativa ocorrência de ponto de exclamação e de ponto de interrogação. Digna de nota, também nessa situação de diálogo, é a discrepância entre a quantidade de ocorrência de travessão e de dois-pontos no sujeito 2 (respectivamente, 30 e 5) e a total ausência deste último sinal nos textos do sujeito 3 , especialmente se contrastada às suas 46 ocorrências de travessão. Ainda a esse respeito, no sujeito 1, embora pouco significativa, também se observa certa tendência ao maior emprego de travessão do que de dois-pontos (respectivamente, 4 e 1, no texto correspondente à proposta 13, e 9 e 7 , na de número 14).

A tendência a essa diferença de ocorrência (em menor ou maior grau) nos três sujeitos explica-se, a nosso ver, talvez em função de uma relação de 
redundância que eles estabelecem entre o emprego de travessão e o de doispontos. Parece-nos, pois, que o que lhes é particularmente significativo nos textos com diálogos é a delimitação de atos de fala-delimitação que o emprego de travessão, por si só, é capaz de fazer.

Com relação à larga ocorrência de travessão, bem como à significativa ocorrência de ponto de exclamação e de interrogação em textos com situações de diálogo, é possível pensar que os sujeitos já começam a manifestar a tendência de distribuir os sinais em função de tipos de textos mais propícios a sua ocorrência. No caso mais particular dos sinais em questão, trata-se, também, a nosso ver, de modos mais específicos de os sujeitos construírem relações entre a escrita e a oralidade, na medida em que, por meio deles, os sujeitos parecem querer marcar em sua expressão gráfica elementos que possivelmente recuperam de sua inserção em práticas da oralidade, tais como, por exemplo, "a curta réplica do diálogo cotidiano (com a diversidade que este pode apresentar conforme os temas, as situações e a composição de seus protagonistas)", ou seja, práticas desenvolvidas com base nesse gênero de discurso primário que é o diálogo, segundo Bahktin (1992, p. 279-280). Em outras palavras, trata-se, pois, de marcas privilegiadas de sua circulação, enquanto escreventes, pelo que supõem talvez ser a gênese da escrita - no sentido atribuído a essa expressão por Corrêa (2003).

Outra questão interessante pode ser levantada a partir de dados do quadro 2. Como se pode observar, nas 6 propostas para produção de textos em versos, houve apenas 3 ocorrências de ponto final, todas num único texto de $\mathrm{S} 1 \mathrm{e}$ - a nosso ver, não por coincidência - justamente nos três lugares em que esse sinal figurava no texto base oferecido aos sujeitos como parte dos dados da proposta temática em questão, a de número 3. Os demais sujeitos, em seus 6 textos em versos, não empregaram sequer uma única vez esse sinal de pontuação.

Além disso, como podemos observar no mesmo quadro, textos em forma de verso mobilizaram muito poucos empregos de pontuação. E, de modo geral, os sinais que ocorreram foram exatamente aqueles que já constavam do apoio gráfico-visual.

Os textos em versos parecem, portanto, adquirir para os sujeitos um caráter predominantemente gráfico - e, conseqüentemente, bem menos calcado em práticas orais, como parece ocorrer com seus textos em prosa. Uma das possíveis explicações para esse fato talvez seja a pouca exposição de nossos sujeitos a esferas da atividade humana (Bahktin, 1992) relacionadas a uma utilização versificada da língua na oralidade, tais como práticas de declamação, 
especialmente em regiões mais urbanizadas do sul e sudeste do país. ${ }^{9}$ Desse modo, as conjunções entre aspectos gramaticais, semânticos e, sobretudo, prosódicos presentes em unidades de escrita delimitadas pelos sinais de pontuação (cf. Chacon, 1998) mostram-se como mais características de textos que, aos sujeitos, pareçam ter vínculo mais forte com situações por eles já vivenciadas em sua inserção por práticas de oralidade.

Passemos, agora, a levantar questões a propósito de (d), aumento de marcas de pontuação ao longo do ano. Observando-se dados expostos nos quadros 2, 3, 4 e 5, é possível visualizar esse aumento tanto no conjunto dos sujeitos quanto (embora com singularidades) em cada sujeito. Vê-se, portanto, que, especialmente no segundo semestre, aumenta para os sujeitos a significação da própria atividade de pontuar no desenvolvimento de suas atividades escritas.

Como se trata de atividades desenvolvidas em contexto escolar e considerando-se, a esse respeito, a importância da escola como agência de letramento (cf. Tfouni, 1994; 2000; Kleiman, 1995) num bairro socialmente menos favorecido (como é o caso do bairro onde se localiza a escola que nossos sujeitos freqüentavam), o aumento de marcas de pontuação pode também estar vinculado a uma maior inserção dos três sujeitos em práticas de letramento de caráter mais institucionalizado, tais como a aprendizagem formal da língua e o contato com livros didáticos e com os chamados paradidáticos. Esse aumento pode, pois, ser visto como índice da circulação do escrevente por fatos mais ligados à aquisição de um código escrito institucionalizado, na medida em que pontuar passa a ser entendido como (mais uma) marca do que, no imaginário dos escreventes, pode significar uma boa escrita (Corrêa, 2003), de acordo com o modelo escolar.

Conseqüentemente, os escreventes parecem já ter começado a atender as expectativas (por eles construídas ou neles projetadas) do que, no imaginário que vão construindo sobre a escrita, significa escrever bem. Afinal, como o aumento de marcas de pontuação ocorre, sobretudo, no segundo semestre, provavelmente tenha aumentado também a atenção que o professor passa a dar às marcas de pontuação dos sujeitos à medida que suas dificuldades ortográficas vão diminuindo.

9 Parece-nos que essa situação poderia ser um pouco diferente no Nordeste do país, uma vez que se podem encontrar repentistas mesmo em regiões mais urbanizadas. $\mathrm{O}$ rap, de norte a sul do país, parece-nos ser um gênero que envolve uma certa utilização versificada da língua, embora não necessariamente desenvolvida com base em aspectos rítmicos como a simetria, largamente observada em textos em versos tradicionais, tais como aqueles que subsidiaram a produção textual de nossos sujeitos. 
Outros fatores podem, porém, estar relacionados a esse aumento. Com efeito, a própria extensão dos textos, maior quanto mais os sujeitos se familiarizam com a atividade de escrever, pode ser vista como um fator que desencadeia um maior número de sinais de pontuação. Mas que não se vincule diretamente o aumento na extensão dos textos ao aumento de sinais. O sujeito 3, por exemplo, no texto correspondente à proposta 13 , teve 23 marcas de pontuação, como podemos observar no quadro 5 . No entanto, essas 23 marcas, todas, ocorreram apenas na primeira página de um texto de três páginas de papel almaço! Fato de algum modo semelhante a esse ocorreu com o sujeito 1, que, num texto de menos de uma página de papel almaço (aquele relativo à proposta 14) teve um total de 29 marcas de pontuação.

Desse modo, embora a maior extensão favoreça, certamente, o maior número de sinais em um texto, a relação dos sujeitos com o texto, ou com a própria proposta temática, ${ }^{10}$ parece determinar mais a importância que os sujeitos atribuem ao ato de pontuar. Além disso, a própria tipologia textual, em si mesma, é digna de destaque quando se trata do aumento de marcas de pontuação. Uma vez que os textos em verso e a instrução de brincadeira mobilizaram nos sujeitos poucos empregos de pontuação, uma menção especial deve ser feita ao tipo de texto para se tematizar não só a importância de se pontuar, como também a própria quantidade de sinais. Em outras palavras, afirmar que as marcas de pontuação aumentaram ao longo do ano, especialmente a partir do segundo semestre, significa afirmar também, em nosso caso, que - ao lado de fatores como a maior familiaridade com a atividade de escrever e a extensão dos textos - a grande quantidade de textos narrativos de nosso material de análise teve parcela altamente significativa nesse aumento.

Passemos, a seguir, para o levantamento de questões relativas a (e), saliência do caráter gráfico da pontuação nas primeiras produções textuais. Os três sujeitos, especialmente nas quatro primeiras propostas, pareceram estar muito mais atentos à própria configuração gráfica dos sinais de pontuação e dos textos básicos que apoiaram suas produções (talvez por se tratarem de propostas que faziam uso de textos em versos) do que ao papel que a pontuação desempenha de delimitar unidades lingüísticas (cf. Chacon, 1998).

Com efeito, nesses seus textos, ao lado de uma grande atenção à quantidade e à disposição gráfica dos versos e, ainda, a determinadas palavras que constavam desses versos, também os sinais utilizados nos textos de apoio,

10 Fazemos essa menção à proposta temática uma vez que os textos cujos temas envolviam animais ou seres como bruxas parecem ter criado situações de maior envolvimento (ou expressividade) na relação sujeito/linguagem. 
CHACON, L. Oralidade e letramento na construção...

bem como seu local de ocorrência, foram particularmente salientes para os sujeitos, como se pode observar nos trechos abaixo, extraídos dos textos correspondentes à proposta 3 do sujeito 1 e do sujeito 3 , respectivamente:

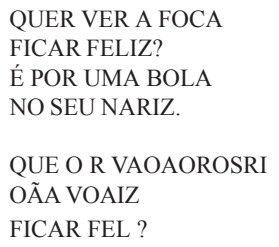

Fato semelhante pode ser verificado nos textos dos três sujeitos correspondentes à proposta 1. Observe-se, primeiramente, a transcrição do texto de apoio:

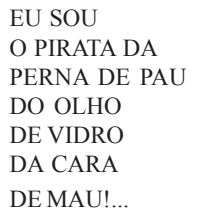

Veja-se, agora, a transcrição dos textos dos sujeitos 1, 2 e 3, respectivamente:

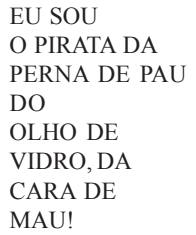


EU SOA

O PIAEI DE

PAU DE VIRA

DO

PIRAL E

MIREIDE!

DE SOU PERTPQA

DE UAU!... PIRTUOQV

Como se pode notar, além da preocupação com a disposição em versos e das tentativas de escrita de palavras do texto original (lembre-se o leitor que se trata da primeira produção textual dos sujeitos, ainda no mês de fevereiro), verifica-se também a importância que os sujeitos deram ao caráter gráfico das marcas de pontuação que observaram no texto original. Marcas como o ponto de exclamação e as reticências foram lembradas pelos sujeitos, ao que nos parece, sobretudo em função de aspectos gráficos relacionados a sua ocorrência no texto original, tais como, no caso do ponto de exclamação, seguir a última palavra do texto (fato destacado pelos sujeitos 1 e 2) ou, no caso das reticências, seguir a palavra pau (fato destacado pelo sujeito 3 , que combina reticências e ponto de exclamação após a tentativa de escrita $U A U$ ) e anteceder a palavra do (fato destacado pelo sujeito 2).

Aliás, essa combinação parece ter sido tão saliente para o sujeito 3 que, em sua tentativa de escrita de outro texto (relativo à proposta 4), sem que esses sinais constassem do material gráfico de apoio (a canção Atirei o pau no gato), esse sujeito os utilizou novamente três meses após tê-los usado em sua primeira produção textual, mas em ordem invertida:

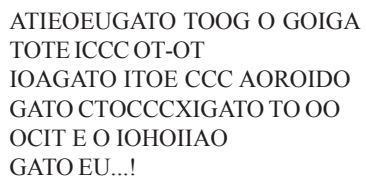

Como esperamos ter demonstrado pelos exemplos, pelo menos em suas primeiras produções textuais é, sobretudo, o estatuto gráfico da pontuação que parece ser mais saliente para os sujeitos, e não o seu papel de delimitar unidades lingüísticas de naturezas diversas. 
Passemos, por fim, ao levantamento de questões relativas a (f), a saber, percepção de conjunção não-isomórfica de elementos de várias naturezas lingüísticas nas estruturas delimitadas por sinais de pontuação.

Em sua grande maioria, as marcas de pontuação de nossos sujeitos tenderam a ocorrer em pontos de delimitação de constituintes ou de grandes unidades textuais. Ao fazerem tais delimitações, nossos sujeitos parecem ter-se guiado pela percepção de conjunções entre elementos gramaticais, semânticos, prosódicos e gráficos, como se pode ver nos trechos abaixo:

\author{
O ELEFANTE ESTAVA SE APROXIMANDO DA BRUXINHA CADA VEZ \\ MAIS. \\ (sujeito 1 , texto correspondente à proposta 6) \\ - eu vou transformar ele em uma estatua. \\ (sujeito 2, texto correspondente à proposta 11) \\ - VOCÊ TAAI? \\ - SIM GATO BOBO! - BOBO É VOCÊ RATO! \\ (sujeito 3, texto correspondente à proposta 15)
}

Às vezes, no entanto, um dos aspectos dessas conjunções parece ser mostrar como particularmente mais saliente para os sujeitos. É o que se pode ver no vínculo que o sujeito 1 estabelece entre o emprego de ponto e a delimitação de unidades gráficas como parágrafos ${ }^{11}$ no texto abaixo (correspondente à proposta 7 ):

num serto dia a bruxa felisbina estava muito cansada e dessidiu deitar no seu sofa com o seu gato entao a bruxa logo foi para a terra dos sonhos.

o gato foi de fininho para pegar a farinha magica da bruxa.

logo depois de pegar a varinha o gato fez uma magica transformando o telefone e o vazo em um hamburguer e um refrigerante.

11 Estamos retomando fato já antecipado acima, ao tratarmos das variações inter-sujeitos. 


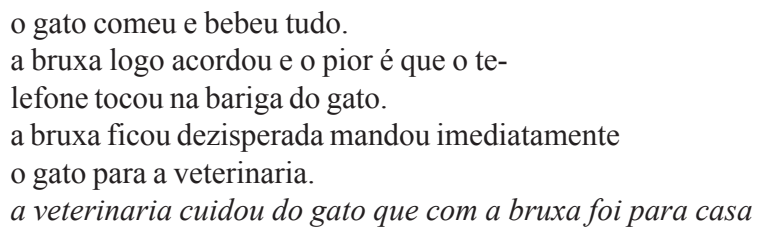

A saliência de aspectos prosódicos, por sua vez, parece ser o que mais particularmente orienta os sujeitos 2 e 3 a empregarem, respectivamente, os pontos de exclamação e de interrogação na delimitação das unidades abaixo:

\author{
mas que chulé! \\ (unidade extraída da produção textual relativa à proposta 10) \\ PARA UM PO QUI NHO VOMO CER A MIGO? \\ (unidade extraída da produção textual relativa à proposta 21)
}

A saliência de aspectos sintáticos e prosódicos parece estar na base dos empregos do ponto pelo sujeito 2 no trecho abaixo (extraído da produção textual referente à proposta 11), na medida em que as unidades delimitadas tanto podem corresponder ao que sintaticamente se define como oração quanto podem corresponder ao que prosodicamente é definido por Nespor e Vogel (1986) como enunciado fonológico:

\footnotetext{
A bruxa levou os gatos para sua casa. Quando chegou em casa a bruxa golocou os gatos em uma jaula. E tranformou um gato em uma vassobra.
} 
O sujeito 2 oferece-nos, ainda, uma hipótese de saliência do aspecto semântico em unidades delimitadas por pontuação, ${ }^{12}$ como se pode ver no exemplo abaixo, extraído do texto relativo à proposta 6 :

\author{
o elefente ficoa paxonado para bruxa fico efeis \\ eles ficofe e um dia e fois no praia no dia \\ que es tava sou. e fono dia docava mei to e \\ na ora de coloca a lir lianca e de pois fonaora \\ de sibeja a brxa fico a sutada
}

Finalmente, uma interessante conjunção entre aspectos prosódicos e gráficos (de finalização de parágrafos) pode ser vista nos exemplos abaixo, nos quais, respectivamente, uma ocorrência de ponto de interrogação é imediatamente seguida daquela de um ponto final e uma ocorrência de ponto de exclamação é também imediatamente seguida daquela de ponto final. Como se verá, esse dado singular (na medida em que só foi verificado em textos do sujeito 1) parece indicar que, pelo menos para esse sujeito, a ocorrência de sinais de pontuação pode se dar, em certos momentos, de modo correlacionado, demarcando diferentes aspectos das unidades delimitadas por pontuação:

\author{
A bruxinha descomfiada pergutou o que você quer \\ de mim?. \\ (trecho extraído do texto relativo à proposta 6) \\ Se eu fosse uma pipa \\ eu gostaria de ser bem colori- \\ do com as cores alegres \\ como amarelo, vermelho, azul, ver- \\ de e rosa escuro e tambem gostaria \\ que meu dono é cuidadozo e \\ lá de cima gostaria de ver
}

12 Conforme antecipamos ao tratarmos das variações inter-sujeitos, as unidades delimitadas por ponto parecem-nos corresponder à distinção da descrição de fatos que se passaram antes e durante a cerimônia de casamento das personagens. 
crianças bricando e não brigar mas não me rasgue por favor!.

(texto relativo à proposta 12$)^{13}$

A partir desses exemplos (e de muitos mais encontrados em nosso corpus), é possível afirmar que a saliência de diferentes aspectos envolvidos na natureza das unidades delimitadas por pontuação indicia diferentes modos de circulação de nossos sujeitos não apenas por fatos ligados ao que, para eles, corresponderia à gênese da (sua) escrita (tais como o destaque a aspectos prosódicos das unidades delimitadas) mas também por fatos ligados à sua inserção em práticas letradas, como as correspondências que eles começam a estabelecer entre iniciais maiúsculas e ponto de demarcação de final de frases, ou mesmo a importância que atribuem ao caráter gráfico dos parágrafos, ou, ainda, a necessidade de delimitar características semânticas de seus textos por ponto, o que, em práticas orais, se poderia fazer por meio de características prosódicas ou conversacionais.

\section{Considerações finais}

Que respostas os lingüistas poderiam ter ao fazerem indagações a respeito de dados da pontuação de textos de estudantes de primeira série do ensino fundamental? Dentre outras que fogem a nosso alcance prever neste momento de nossa própria indagação, várias respostas seriam possíveis.

13 Conforme relato da professora que coletou os textos, todos os alunos tiveram muito contato, em sala de aula, com histórias em quadrinhos. Desse modo, a dupla pontuação no sujeito 1 pode também estar relacionada com sua exposição a esse tipo de material gráfico - o que reforçaria os vínculos que estamos estabelecendo, em nosso estudo, entre a utilização da pontuação e fatos mais ligados à inserção de nossos sujeitos em diferentes práticas de letramento. Além disso, é interessante observar que, noutra situação, o mesmo sujeito 1, assim como os demais, evitam redundância de sinais (tais como a não correspondência entre dois-pontos e travessão). Desse modo, não utilizar sinais redundantes numa situação e utilizálos em outra remete-nos, parece, a diferentes modos de relação dos sujeitos com a língua, na medida em que, possivelmente, identificam uma única condição lingüística para seu emprego nas situações em que os vêem como redundantes ou mais de uma condição lingüística nas situações em que os concatenam (por exemplo, no caso em questão, demarcar o final de um contorno entonacional e o final de um enunciado). 
A nosso ver, ao pontuar, os três sujeitos de nosso estudo manifestaram a percepção de que o texto, em sua modalidade escrita, é segmentável e de que os sinais de pontuação podem demarcar o produto lingüístico segmentado. Com isso, os sujeitos manifestaram também a percepção de que haveria pontos mais específicos ou prováveis, a seu ver, para efetuarem segmentações no texto.

Conseqüentemente, pelo fato de fazerem delimitações, podemos atribuir aos sujeitos uma intuição de constituintes lingüísticos, tanto maiores quanto menores, e, desse modo, podemos fazer especulações sobre suas relações com a própria língua. No entanto, na medida em que a delimitação de constituintes feita por esses sujeitos coincidiu ou não com aqueles constituintes propostos pelas diferentes teorias lingüísticas, essa pontuação muitas vezes instável dos sujeitos pode levantar dúvidas nos lingüistas a respeito de constituintes que já supõem como suficientemente definidos nas várias dimensões da gramática.

Ainda a respeito da delimitação de unidades lingüísticas, as marcas de pontuação no início da aquisição da escrita servem também para os lingüistas se interrogarem sobre possíveis interfaces dos componentes da gramática, tanto aquelas já tidas como mais estabelecidas (sintaxe e prosódia, por exemplo), quanto outras ainda não - suficientemente - exploradas (por exemplo: prosódia e paragrafação, na escrita). Como procuramos demonstrar, diferentes modos de integração de aspectos lingüísticos parecem estar na base de como nossos sujeitos se orientam para utilizarem marcas de pontuação em seus textos.

Aliás, se os definimos, experimentalmente, como sujeitos, temos também outras razões para assim nomeá-los, como, por exemplo, o fato de que seus modos mais singulares de pontuar pareceram-nos indiciar suas tentativas de tomar a escrita como própria (Soares, 1998) e não como mero objeto de conteúdo escolar. Com efeito, se, por um lado, aumentaram as marcas de pontuação que nossos sujeitos fizeram em seus textos, não se pode afirmar que esse aumento tenha sido efeito de uma progressão mais ou menos "natural" de aprendizagem ou de aquisição de conhecimentos. Basta ver, pelos quadros 3, 4 e 5, que esse aumento se deu de modo diferenciado entre nossos sujeitos. Assim, ao invés de "progressão de aprendizagem" ou de "aquisição de conhecimentos", preferimos entender tanto esse aumento quanto a forma singular como ele se deu entre nossos três sujeitos como "mudanças de posição relativamente à fala do outro, à língua e, em conseqüência, em relação à própria fala" (Lemos, 2002, p. 56) - e à própria escrita, acrescentaríamos nós.

Se, como acreditamos, essas mudanças de posição se dariam em relação à própria fala e/ou à própria escrita e se os efeitos dessa mudança se fariam sentir na atividade de pontuação de nossos sujeitos, sentimo-nos autorizados a 
dizer que eles, de algum modo, manifestam não a intuição de uma heterogeneidade da linguagem que se mostraria na escrita, mas a de uma heterogeneidade constitutiva da própria escrita (cf. Corrêa, 2003), na medida em que seu trânsito por práticas de oralidade e de letramento se mostra sobreposto ou salientado nas diferentes maneiras como esses sujeitos sinalizam seus textos por meio da pontuação. Ou seja, é constitutiva da própria atividade de pontuar - e, por extensão, de escrever - a inscrição histórica do sujeito escrevente em práticas de oralidade e de letramento. Caso assim não fosse, como explicar a distribuição mais regular da pontuação em quase todas as propostas temáticas no sujeito 1 e a sua concentração nas primeiras e nas últimas propostas no sujeito 3? Como explicar, ainda em relação ao sujeito 3, o fato de que, em suas primeiras produções, o caráter gráfico dos sinais parece ter se mostrado para ele como mais saliente e, nas últimas propostas, com expressiva quantidade de exclamações, interrogações e, especialmente, travessões, o caráter prosódico parece ter-lhe sobressaído? E o que dizer do emprego de aspas no seguinte trecho do sujeito 1:

- Pronto agora esta ótima mas falta o pa-

pai Noel.

Disse a bruxinha e um papai Noel apareceu do nada e disendo

- Hou hou hou quem disse "falta papai noel" aquí estou eu e que é esse presete?

extraído de seu texto correspondente à proposta 14 ?

Acreditamos que diferenças como essas justamente demonstram em que medida a inserção em práticas orais e em práticas letradas pode atuar na atividade de escrita e em que medida esse trânsito se marca nos aspectos que se mostram como mais salientes para os sujeitos (caso da pontuação mais gráfica ou mais "oral" do sujeito 3, marcando seus dois diferentes trânsitos, ou o caso bastante singular de emprego de aspas no sujeito 1, índice - parece-nos - de seu trânsito mais atento por práticas de letramento). Em outras palavras, na base da aquisição da escrita, também a percepção do que Corrêa (2003) acertadamente define como a heterogeneidade da própria escrita. 


\title{
RESUMO
}

Neste estudo, tivemos como preocupação a busca de fatos lingüísticos possivelmente envolvidos na aquisição da pontuação. Para tanto, selecionamos ocorrências de pontuação em 45 textos produzidos em situação escolar por três sujeitos que freqüentaram a primeira série do ensino fundamental numa escola municipal de São José do Rio Preto (SP) - sendo 15 textos de cada sujeito. Como principais tendências relacionadas ao emprego de sinais de pontuação nesses textos observamos: a) variação inter-sujeitos; b) variação intra-sujeitos; c) variação em função de tipo de textos; d) aumento de marcas de pontuação ao longo do ano; e) saliência do caráter gráfico da pontuação nas primeiras produções textuais; e f) percepção de uma conjunção não isomórfica de elementos de várias naturezas lingüísticas. Como hipóteses explicativas para essas tendências, destacamos diferentes modos de relação dos sujeitos com a língua e, sobretudo, sua inscrição histórica em práticas de oralidade e de letramento, sobrepostas ou salientadas no emprego dos sinais.

Palavras-chave: pontuação, aquisição da escrita.

\begin{abstract}
In this article, our aim was to search for linguistic issues possibly involved in punctuation acquisition. In such a way, we extracted punctuation occurrences from 45 texts produced by three elementary school first degree students from São José do Rio Preto (SP state, Brazil) - 15 texts of each student. Data indicated six main tendencies: a) intersubjects variation; b) intrasubjects variation; c) variation resulting from different types of text; d) increase of punctuation across time; e) saliency of graphic character of punctuation in the first texts; and f) perception of a non-isomorphic integration of different linguistic elements. We suggested that different kinds of subject/language relationship and facts from orality and literacy gave the main support to punctuation activity of our subjects.
\end{abstract}

Key-words: punctuation, writing acquisition. 


\section{REFERÊNCIAS}

ABAURRE, M. B. M. O que revelam os textos espontâneos sobre a representação que faz a criança do objeto escrito? In: KATO, M. A. (Org.). A concepção da escrita pela criança. Campinas: Pontes, 1988. p. 135-142.

. Oral and written texts: beyond the descriptive illusion of similarities and differences. [S.1.: s.n.], 1989.

- A relevância dos critérios prosódicos e semânticos na elaboração de hipóteses sobre segmentação na escrita inicial. Boletim da Abralin, v. 11, p. 203-217, 1991.

. Os estudos lingüísticos e a aquisição da escrita. In: CASTRO, M. F. P. (Org.). $O$

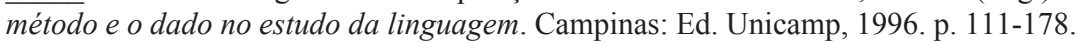

. Horizontes e limites de um programa de investigação em aquisição da escrita. In: LAMPRECHT, R. R. (Org.). Aquisição da linguagem: questões e análises. Porto Alegre: Ed. PUC-RS, 1999. p. 167-186.

; CAGLIARI, L. C. Textos espontâneos na primeira série: evidência da utilização, pela criança, de sua percepção fonética para representar e segmentar a escrita. Cadernos Cedes, São Paulo, v. 14, p. 25-29, 1985.

; SILVA, A. O desenvolvimento de critérios de segmentação na escrita. Temas em psicologia, São Paulo, v. 1, p. 89-102, 1993.

; FIAD, R. S.; MAYRINK-SABINSON, M. L. T. Cenas de aquisição da escrita: o trabalho do sujeito com o texto. Campinas: Mercado de letras, 1997.

BAHKTIN, M. Estética da criação verbal. São Paulo: Martins Fontes, 1992.

CAGLIARI, L. C. Alfabetização e lingüística. São Paulo: Scipione, 1993.

. Alfabetizando sem o BA-BÉ-BI-BÓ-BU. São Paulo: Scipione, 1998.

CAPRISTANO, C. C. Aspectos de segmentação na escrita infantil. São José do Rio Preto: 2003. Dissertação (Mestrado em Estudos Lingüísticos) - Instituto de Biociências, Letras e Ciências Exatas (Ibilce), Universidade Estadual Paulista (Unesp).

CHACON, L. Ritmo da escrita: uma organização do heterogêneo da linguagem. São Paulo: Martins Fontes, 1998.

. Algumas palavras sobre a aquisição da pontuação. In: LAMPRECHT, R. R. (Org.). Aquisição da linguagem: questões e análises. Porto Alegre: Ed. PUC-RS, 1999. 
CHACON, L. Oralidade e letramento na construção...

CORRÊA, M. L. G. O modo heterogêneo de constituição da escrita. São Paulo: Martins Fontes, 2003. No prelo.

KLEIMAN, A. (Org.). Os significados do letramento. Campinas: Mercado das Letras, 1995.

LEMOS, C. T. G. Das vicissitudes da fala da criança e de sua investigação. Cadernos de Estudos Lingüísticos, Campinas, v. 42, p. 41-96, jan.jul. 2002.

NESPOR, M.; VOGEL, I. Prosodic phonology. Dordrechet: Foris, 1986.

SILVA, A. Alfabetização: a escrita espontânea. São Paulo: Contexto, 1994.

SOARES, M. Letramento: um tema em três gêneros. Belo Horizonte: Autêntica, 1998.

TFOUNI, L. V. Perspectivas históricas e a-históricas do letramento. Caderno de Estudos Lingüisticos, Campinas, v. 26, p. 49-62, jan./jun. 1994.

. Letramento e alfabetização. São Paulo: Cortez, 2000. 